\title{
Quantitation in EMG
}

\author{
K. Ming Chan and William F. Brown
}

\begin{abstract}
The neuromuscular system may be affected by disorders of the central nervous system as well as other disorders affecting motoneurons, axons, neuromuscular transmission, the sarcolemmal membrane, the contractile elements and other components of the muscle fibers themselves. One or a combination of these possibilities can present in patients in the critical care unit. This paper reviews various qualitative and quantitative methods for assessing the various components of the peripheral contributions to the electrical and force output as well as the central motor drive to motoneurons. These methods all have their own strengths and weaknesses but many are complementary and together, can provide important diagnostic and prognostic information to guide management.
\end{abstract}

RÉSUMÉ: Quantification à l'EMG. Le système neuromusculaire peut être affecté par les maladies du système nerveux central ainsi que par d'autres maladies qui affectent les motoneurones, les axones, la transmission neuromusculaire, la membrane sarcolemmique, les éléments contractiles et les autres composantes des fibres musculaires elles-mêmes. Une ou plusieurs de ces pathologies peuvent survenir chez les patients hospitalisés à l'unité de soins intensifs. Nous revoyons différentes méthodes qualitatives et quantitatives pour évaluer les contributions périphériques aux mesures électriques et de force ainsi que l'influx moteur central vers les montoneurones. Ces méthodes ont toutes leurs forces et leurs faiblesses, mais plusieurs sont complémentaires les unes des autres et peuvent toutes fournir des informations diagnostiques et pronostiques importantes pour élaborer un traitement.

Can. J. Neurol. Sci. 1998; 25: S27-S31

The neuromuscular system may be affected in a variety of ways in critically ill patients. ${ }^{1-8}$ Disorders of the central nervous system may, for example, affect the patient's ability to effectively recruit motoneurons, while other disorders may affect motoneurons, axons, neuromuscular transmission, the sarcolemmal membrane, the contractile elements and other components of the muscle fibers themselves. This wide range of potential problems may also be found in patients with severe neuromuscular diseases who need intensive care..$^{9-11}$ Because one or more of the various components of the neuromuscular system may be affected at one time or another in the course of a patient's illness, it may be difficult, if not impossible, to identify and weigh the relative importance of specific factors contributing to any given patient's weakness.

One way to examine the various factors affecting neuromuscular performance is to begin by asking how the neuromuscular system as a whole might be assessed, then to consider how each sub-component of the neuromuscular system might be examined and finally to consider how these approaches might be applied in the setting of critical illness related to neuromuscular disorders.

\section{Assessing the Force Output of Muscles}

Clinical examination of the neuromuscular system is based largely on the assessment of strength. For this reason, and because the ability to generate and sustain force is an essential measure of the capacity of the neuromuscular system to function properly, currently available methods for assessing the force output of muscles will be examined. These methods may be use- fully divided in the following manner: 1) assessment of maximum voluntary contractions, 2) assessment of the force generated in response to direct or indirect muscle stimulation, 3) assessment of the "central drive" to motoneurons by magnetoelectrical cortical stimulation.

\section{The Assessment of Maximum Voluntary Contractions}

Testing strength at the bedside is usually carried out by asking the subject to make a maximal, usually isometric, contraction against the resistance provided by the examiner. From the quality and strength of the contraction assessed subjectively by the examiner, inferences are made about the presence or absence of any weakness and, in the case of the latter, whether the effort made by the subject was sufficiently full to justify the conclusion that weakness is indeed present. The determination of what represents normal strength is clearly a subjective assessment and based on the examiner's experience of what might reasonably be expected of healthy subjects of similar age, sex and body build when they put out their "best effort". Strength is graded in some fashion, most commonly by applying the MRC scale. 12 This method has proven to be invaluable and reasonably reproducible in the hands of experienced examiners and an effective means of determining the overall pattern of weakness as well as the severity of the weakness. However, the method, despite its undoubted clinical utility in service, suffers from several pitfalls. Some of

From the Department of Neurology. New England Medical Center. Boston. Massachusetts.

Reprint requests to: William F. Brown. Department of Neurology, New England Medical Center, \#314, 750 Washington Street, Boston, Massachusetts U.S.A. 02111 
these include: 1) Subjects may fail to make a full effort because the task and effort required has not been fully explained to the subject by the examiner or, if explained, are not understood. Both of these are common in intensive care settings for a variety of reasons. 2) The subject may find it difficult to comply because of discomfort. 3) The assessment of strength depends on the experience of the examiner. 4) There is no truly satisfactory and universally accepted definitions for the grades. 5) The scales are not linear. For example, the difference for the MRC scale between grade 3 (anti-gravity strength) and 2 (less than antigravity) is less than between grade 4 (less than full strength) and 3. This non-linearity imposes several major problems including varying sensitivity to strength change and also makes it inappropriate for using the more powerful parametric statistics for analysis. ${ }^{13,14}$

The assessment of maximum voluntary contractions may be enhanced by the substitution of a force transducer for the subjective assessment of a clinical examiner. One such method, the Tufts Quantitative Neuromuscular Examination (TQNE) measures the force generated by a variety of upper and lower extremity muscles and has proven to be a valuable tool for serially assessing the strength of representative muscle groups in clinical trials in ALS. ${ }^{15-17}$ However, the method cannot be readily applied to the intrinsic hand muscles or a variety of other smaller muscle groups. With some modification, quantification of the contractile force generated by isometric voluntary contractions also lends itself to an examination of fatigue by assessing the ability of subjects to sustain steady or repeated maximal or submaximal voluntary contractions.

One major pitfall of using voluntary contraction as a means of assessing the force output of a muscle is that such contractions necessarily involve both the "central" and peripheral limbs of the neuromuscular system. Any loss of strength or increase in fatigue could, therefore, be a consequence of either a "central" failure to sufficiently drive the motoneuron pool or alternatively a failure somewhere in the peripheral arm of the neuromuscular system between the motoneuron and the muscle.

\section{Assessment of the Force Generated in Response to Direct or Indirect Muscle Stimulation}

There are several ways to assess the "central" component to the force generated by a maximum voluntary contraction. One method is to deliver a single supramaximal stimulus or a pair of stimuli to enhance the response to the peripheral nerve while the subject attempts a maximal voluntary contraction. The size of such an "interpolated twitch" is roughly proportional to the extent to which the subject fails to recruit all the motor units within the muscle. ${ }^{18-21}$ The force generated by a maximum voluntary contraction may also be compared with the force generated in response to a supramaximal train of electrical stimuli delivered to the motor nerve in the case of indirect stimulation or muscle in the case of direct stimulation, with a frequency sufficient to evoke the maximum force. Generally such direct and indirect stimulation evokes a force very similar in peak force and rate of decline (fatigue) to the force profile of a maximal voluntary contraction, especially where subjects are trained and well motivated to make a maximal voluntary effort. However, such peripheral methods for assessing the maximum force output of a muscle are decidedly uncomfortable when applied to whole muscles or muscle groups.

\section{Assessment of the "Central Drive" to Motoneurons by Magneto-electrical Cortical Stimulation}

Magneto-electrical stimulation presynaptically stimulates pyramidal track neurons in the motor cortex, especially the direct cortico-motoneuronal component of the motor cortical drive to spinal motoneurons. The latter is a subset of the central motor system which includes the forebrain, premotor cortex, supplementary motor cortex, sensori-motor cortex, basal ganglia, cerebellum and related brainstem structures. Maximal response of a muscle group requires a low level of background voluntary contraction, i.e., "facilitation" of those muscles. This helps the operator to achieve a degree of selectivity of activation of the particular target muscles being studied. To examine the integrity of the central vs. peripheral arms of the neuromuscular system, the maximum compound action potential and twitch evoked by supramaximal stimulation of the motor nerve may be compared with the corresponding parameters evoked by a maximal magneto-electrical stimulus delivered to the motor cortex. ${ }^{22.23}$ Although the muscles activated by magneto-electrical stimulation are more extensive than peripheral nerve stimulation, these comparative ratios are still useful indicators for gauging the relative integrity of the central and peripheral components of the motor system.

\section{Assessing the Electrical Properties of the Motor System}

\section{Examination of the Recruitment Patterns and Firing Rates of Motoneurons During Voluntary Contractions}

The firing rates of motor units can provide useful indications to the probable underlying cause of weakness, whether "central", motoneuronal or in the muscle. There is clear evidence that 1 ) motoneurons are recruited in an orderly manner. ${ }^{24-30} 2$ ) force is governed by the number of motoneurons recruited and the firing rates of those motoneurons and 3) the motor system exhibits "muscular wisdom" whereby the firing rates of motoneurons are reduced during the course of a fatiguing contraction to maintain the force of the contraction as best as possible. ${ }^{31-33}$

\section{Motoneurons: Motor Unit Number Estimation}

The number and functional capacities of motoneurons (or motor units) are important additional measures of the neuromuscular system. Indirect indications of the number of motor units in a muscle may be gathered from the size of the maximum compound action potential evoked by a supramaximal stimulus delivered to the motor nerve or by judging from the number of motor units recruited at various intensities of voluntary contractions. However, more direct clues to the probable numbers of motor units may be obtained from several recently introduced and improved modifications $\mathrm{s}^{34-41}$ to the original method for estimating the number of motor units in a muscle (or muscle group) introduced in 1971 by McComas. ${ }^{42}$ Some of these methods are based on electrical stimulation of the motor nerve and are most applicable to distal muscles, while others may be applied to proximal muscles. For all of these techniques, the estimate of the number of motor units within any particular muscle or muscle group is more difficult with healthy young subjects because the determination of the average motor unit action potential size is based on a relatively small sample of motor units relative to the total number of motor units in the muscle. The latter situation stands in 
contrast to some pathological conditions where the actual number of motor units can be determined with relative ease in serial studies. The importance of a more direct estimate of the number of motor units rather than guessing the number of motor units from the size of the maximal compound muscle action potential is that muscle wasting disorders may appreciably reduce the size of the maximal compound muscle action potential with no appreciable losses of motor axons or motor units.

However, the total number of motor units is only part of the motor unit story. Equally important is a knowledge of the sizes and functional status of the surviving motor units. ${ }^{43-47}$ For example, healthy elderly adults can generate contractile forces equivalent to younger adults with roughly one-half the number of motor units. ${ }^{48,49}$ This contrasts with some ALS patients who may, in some instances, possess similar numbers of motor units to their age-matched controls but are unable to generate or sustain equivalent forces because a large fraction of the surviving motor unit pool may be "dysfunctional". 50.51 The functional status of surviving motor units may also be assessed from determining the sizes of the surface or intramuscularly "macro" detected motor unit action potentials. ${ }^{35,52,53}$ More difficult is the task of assessing the contractile properties of single motor units, including their contractile speeds, twitch and tetanic tensions and fatigue characteristics. ${ }^{43,44,46,47}$ The task of measuring the conduction velocities of single motor axons for distal intrinsic hand muscles is easier and provides a better profile of what is happening to transmission in motor nerve fibers than the maximum motor conduction velocity which only reflects conduction in the fastest motor nerve fibers. ${ }^{54-57}$

Assessing the innervation patterns of single motor units provides much valuable quantitative information about the presence or absence of reinnervation as well as the stability of axonal and neuromuscular transmission. Such information may be gleaned from a careful examination of the number of muscle fibers in each motor unit generating spikes within the detection zone of the electrode (fiber density). ${ }^{58-60}$ The finding of increased jitter and perhaps blocking are indications of abnormal neuromuscular transmission, either at junctions undergoing degenerative changes or in immature, recently formed neuromuscular junctions.

\section{Peripheral Motor Conduction}

Methods exist for systematically examining conduction in motor nerve fibers between the spinal roots and close to the motor point. ${ }^{61-64}$ Such methods make it possible to reliably identify conduction slowing, abnormal temporal dispersion and conduction block throughout almost the entire course of the peripheral nervous system, at least for the motor nerve supply to the intrinsic hand muscles and lateral calf and posterior calf muscles. An example of their utility is illustrated in Figure 1. With the addition of magneto-electrical cortical stimulation, conduction between the motor cortex and the spinal roots may also be identified as illustrated by Figure 2 . Of particular relevance to the intensive care setting is the status of the respiratory muscles of those patients who are ventilator dependent. Bolton and co-workers have recently described several useful techniques to study the diaphragm. ${ }^{10,65}$

\section{Neuromuscular Transmission}

Neuromuscular transmission may be assessed in several ways including: (a) Looking for variations in shape and size of

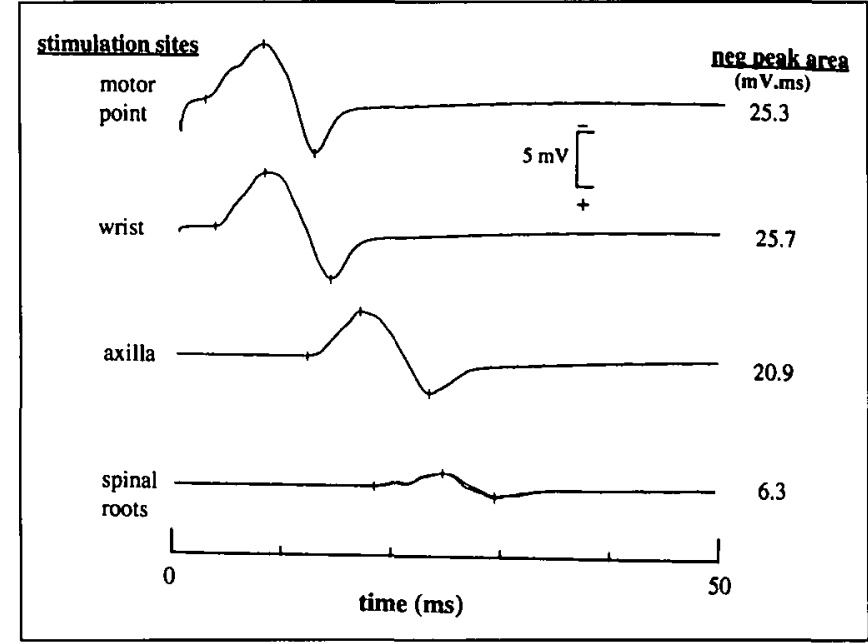

Figure 1: This 56-year-old man presented with respiratory symptoms suggestive of a viral infection 1 week prior to developing acute and rapidly progressive weakness affecting all four limbs and the respiratory muscles. Although he had marked weakness of the intrinsic hand muscles, this study of the hypothenar motor fibers carried out 4 days after the onset of weakness revealed that conduction between the hypothenar muscles and axilla was normal except for the fact that the sizes of the maximal compound muscle action potentials were at the lower limit of normal. In this case, conduction was slowed and block was present only between the spinal roots (stimulated by means of a Devices DI80 high voltage electrical stimulator) and the axillary stimulation site.

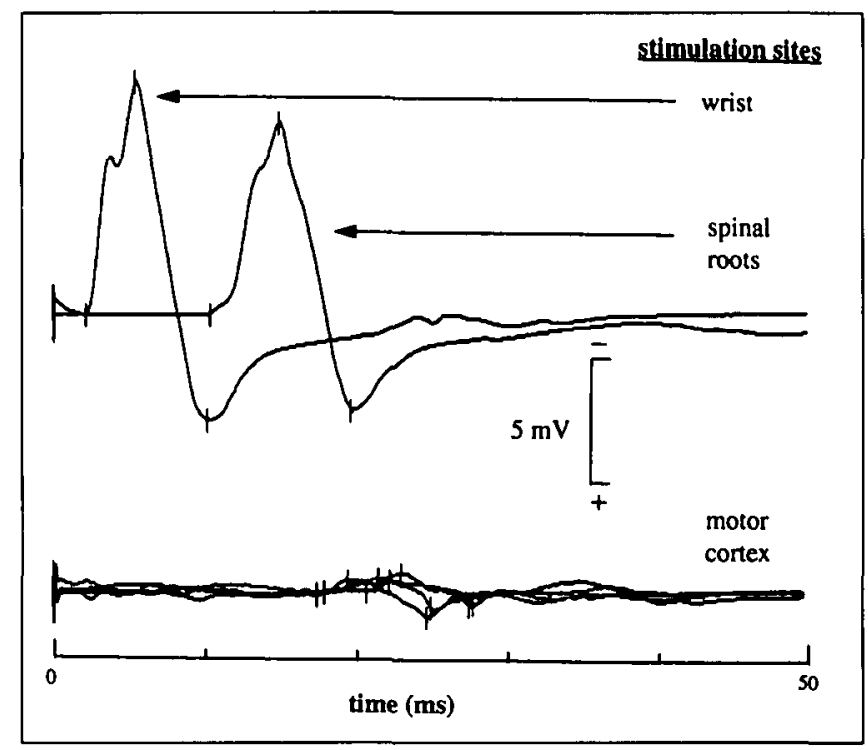

Figure 2: This 74-year-old lady slipped and struck her forehead against the curb during the fall. She subsequently developed tetraparesis, greater in the arms than the legs. Conduction in the hypothenar motor fibers between the motor point and spinal roots was normal (upper traces). However, the latency difference between the " $M$ " potential evoked by magneto-electrical cortical stimulation in the hypothenar muscles (lower superimposed traces), and the latter in response so supramaximal stimulation of the spinal roots, was prolonged. As well, the hypothenar response to cortical stimulation was reduced in size. Although less severe, the same pattern of conduction abnormalities was also present in her lower limb motor conduction studies. These electrophysiological results supported the clinical diagnosis of central cord syndrome. MRI of the cervical spine showed extensive osteophyte formation but no fracture or dislocation was present. 
voluntarily recruited or electrical stimulus evoked motor unit action potentials as detected with either surface or intramuscular electrodes. ${ }^{66}$ In the case of the latter, abnormal jitter and sometimes blocking may be readily seen even with concentric needle recordings and may be taken as indications of instabilities in neuromuscular transmission. (b) Looking for abnormal decrements in the compound muscle action potential or motor unit action potentials in the case of single motor units, in response to repetitive stimulation. (c) Measuring the jitter and incidence of blocking in single muscle fibers using a single fiber EMG electrode and either voluntarily recruited or carefully graded electrical stimulation of presynaptic motor axons to recruit the muscle fibers (stimulation single fiber EMG). ${ }^{58-60}$

\section{Muscle}

Muscle may be examined with several tools. First, using needle electrodes, the sizes of motor unit action potentials may be assessed as a means of identifying patterns indicative of either a reinnervation or a myopathic process using voluntarily or peripheral nerve stimulus recruited motor units. ${ }^{67-70}$ The same tool may be used to detect "denervation activity", myotonic and neuromyotonic activity and hypoexcitability of muscle fibers, the last of which may be associated with hypokalemic paralysis or ischemic-infarction of muscle.

Second, CT and MRI may be profitably employed to assess muscle atrophy, especially as this affects the iliopsoas and other muscles whose bulk may be difficult, if not impossible, to assess clinically. ${ }^{71.72}$

Lastly, muscle biopsies may be used to identify fiber type grouping as an indication of reinnervation, muscle atrophy, fiber type preponderance as well as more specific muscle pathological changes which may prove invaluable in assessing the primary or, in some instances, secondary neuromuscular disorders affecting a given patient. ${ }^{73,74}$

\section{SUMMARY}

Many of the preceding tools for assessing the neuromuscular system are simply not applicable in the setting of an intensive care unit because they are too cumbersome, technically difficult or impractical. However, some of the methods could usefully be applied in special circumstances to shed more light on the pathogenesis of some of the complex neuromuscular disorders in the intensive care unit. Using a combination of these available methods maximizes the chances of establishing the nature, severity and sites of the neuromuscular deficits. This forms an important first step when trying to determine the most appropriate interventions.

\section{REFERENCES}

1. Bolton CF, Gilbert JJ, Hahn AF, et al. Polyneuropathy in critically ill patients. J Neurol Neurosurg Psychiatry 1984; 47: 1223-1231.

2. Giostra E, Magistris MR, Pizzolato G, et al. Neuromuscular disorder in intensive care unit patients treated with pancuronium bromide. Occurrence in a cluster group of seven patients and two sporadic cases, with electrophysiologic and histologic examination. Chest 1994; 106: 210-220.

3. Spitzer AR, Giancarlo T, Maher L, et al. Neuromuscular causes of prolonged ventilator dependency. Muscle Nerve 1992; 15: 682686.

4. Wijdicks EF, Litchy WJ, Harrison BA, et al. The clinical spectrum of critical illness polyneuropathy. Mayo Clin Proc 1994; 69: 955-959.
5. Witt NJ, Zochodne DW, Bolton CF, et al. Peripheral nerve function in sepsis and multiple organ failure. Chest 1991; 99: 176-184.

6. Young GB, Bolton CF, Austin TW, et al. The encephalopathy associated with septic illness. Clin Invest Med 1990; 13: 297-304.

7. Zochodne DW, Bolton CF, Wells GA. Critical illness polyneuropathy - a complication of sepsis and multiple organ failure. Brain 1987; 110: 819-842.

8. Zochodne DW, Ramsay DA, Saly V, et al. Acute necrotizing myopathy of intensive care: electrophysiological studies. Muscle Nerve 1994; 17: 285-292.

9. Bolton CF. Neuropathies in the critical care unit. Br J Hosp Med 1992; 47: 358-360.

10. Maher J, Rutledge F, Remtulla $\mathrm{H}$, et al. Neuromuscular disorders associated with failure to wean from the ventilator. Intensive Care Med 1995; 21: 737-743.

11. Zochodne DW, Bolton CF. Neuromuscular disorders in critical illness. Baillieres Clin Neurol 1996; 5: 645-671.

12. Medical Research Council. Aids to the Examination of the Peripheral Nervous System. England: Her Majesty's Stationary Office, 1981.

13. Andres PL, Thibodeau LM, Finison LJ, et al. Quantitative assessment of neuromuscular deficit in ALS. Neurol Clin 1987; 5: 125141 .

14. Dvir Z. Grade 4 in manual muscle testing: the problem with submaximal strength assessment. Clin Rehabil 1997; 11:36-41.

15. Andres PL, Hedlund W, Finison L, et al. Quantitative motor assessment in amyotrophic lateral sclerosis. Neurology 1986; 36 : $937-$ 941.

16. McGuire D. Garrison L, Armon C, et al. Relationship of the Tufts Quantitative Neuromuscular Exam (TQNE) and the Sickness Impact Profile (SIP) in measuring progression of ALS. SSNJV/CNTF ALS Study Group. Neurology 1996; 46: 14421444.

17. Pradas J, Finison L, Andres PL, et al. The natural history of amyotrophic lateral sclerosis and the use of natural history controls in therapeutic trials. Neurology 1993; 43: 751-755.

18. Allen GM, Gandevia SC, Mckenzie DK. Reliability of measurements of muscle strength and voluntary activation using twitch interpolation. Muscle Nerve 1995; 18: 593-600.

19. Dowling JJ, Konert E, Ljucovic P, et al. Are humans able to voluntary elicit maximum muscle force? Neurosci Lett 1994; 179: 2528.

20 Hales JP, Gandevia SC. Assessment of maximal voluntary contraction with twitch interpolation: an instrument to measure twitch responses. J Neurosci Meth 1988; 25: 97-102.

21. Mckenzie DK, Bigland-Ritchie B, Gorman R, et al. Central and peripheral fatigue of human diaphragm and limb muscles assessed by twitch interpolation. J Physiol 1992; 4545: 643-656.

22. Gandevia SC, Allen GM, Butler JE, et al. Supraspinal factors in human muscle fatigue: evidence for suboptimal output from the motor cortex. J Physiol 1996; 490: 529-530.

23. Taylor JL, Butler JE, Allen GM, et al. Changes in motor cortical excitability during human muscle fatigue. J Physiol 1996; 490: 519-528.

24. Goslow GE, Cameron WE, Stuart DG. The fast twitch motor units of cat ankle flexors. 2. Speed-force relations and recruitment order. Brain Res 1977; 134: 47-57.

25. Henneman E. Relation between size of neurons and their susceptibility to discharge. Nature 1957; 1345-1347.

26. Henneman E, Somjen G, Carpenter DO. Functional significance of cell size in spinal motoneurons. J Physiol 1965; 560-580.

27. Milner-Brown HS, Stein RB, Yemm R. The contractile properties of human motor units during voluntary isometric contractions. J Physiol 1973; 228: 285-306.

28. Milner-Brown HS, Stein RB, Yemm R. Changes in firing rate of human motor units during linearly changing voluntary contractions. J Physiol 1973; 230: 371-390.

29. Olson CB, Carpenter DO, Henneman E. Orderly recruitment of muscle action potentials. Arch Neurol 1968; 19: 591-597.

30. Thomas CK, Ross BH, Calancie B. Human motor-unit recruitment during isometric contractions and repeated dynamic movements. J Neurophysiol 1987; 57: 311-324. 
31. Macefield G, Hagbarth KE, Gorman R, et al. Decline in spindle support to alpha motoneurones during sustained voluntary contractions. J Physiol 1991; 440: 497-512.

32. Macefield VG, Gandevia SC, Bigland-Ritchie B, et al. The firing rates of human motoneurones voluntarily activated in the absence of muscle afferent feedback. J Physiol 1993; 471: 429 443.

33. Marsden CD, Meadows JC, Merton PA. Muscular wisdom. In: Desmedt, ed. Prog Clin Neurophysiol: Motor Control. Basel: Karger, 1983; 169-211.

34. Ballantyne JP, Hansen. A new method for the estimation of the number of motor units in a muscle. J Neurol Neurosurg Psychiatry 1974; 37: 907-915.

35. Brown WF. A method for estimating the number of motor units in thenar muscles and the changes in motor unit count with aging. $J$ Neurol Neurosurg Psychiatry 1972; 35: 845-852.

36. Daube JR. Estimating the number of motor units in a muscle. J Clin Neurophysiol 1995; 12: 585-594.

37. Doherty T, Simmons Z, O'Connell B, et al. Methods for estimating the numbers of motor units in human muscles. J Clin Neurophysiol 1995; 12: 565-584.

38. Galea $V$, de Bruin $H$, Cavasin $R$, et al. The numbers and relative sizes of motor units estimated by computer. Muscle Nerve 1991; 14: 1123-1130.

39. Slawnych M, Laszlo $C$, Hershler C. Motor unit estimates obtained using the new "MUESA" method. Muscle Nerve 1996; 19: 626636.

40. Stashuk DW, Doherty TJ, Kassam A, et al. Motor unit number estimates based on the automated analysis of $\mathrm{F}$ responses. Muscle Nerve 1994; 17: 881-890.

41. Stein RB, Yang JF. Methods for estimating the number of motor units in human muscles. Ann Neurol 1990; 28: 487-495.

42. McComas AJ. Electrophysiological estimation of the number of motor units within a human muscle. J Neurol Neurosurg Psychiatry 1971; 34: 121-131.

43. Chan KM, Andres LP, Brown WF. Longitudinal study of the contractile and electrical properties of single human motor units. Muscle Nerve 1996; 19: 1189.

44. Stein RB, French AS, Mannard A, et al. New methods for analysing motor function in man and animals. Brain Res 1972; 40: 187-192.

45. Stephens JA, Usherwood TP. The mechanical properties of human motor units with special reference to their fatiguability and recruitment threshold. Brain Res 1977; 125: 91-97.

46. Taylor A, Stephens JA. Study of human motor unit contractions by controlled intramuscular microstimulation. Brain Res 1976; 117 : 331-335.

47. Thomas CK, Johansson RS, Westling G, et al. Twitch properties of human thenar motor units measured in response to intraneural axon stimulation. J Neurophysiol 1990; 64: 1339-1346.

48. Doherty TJ, Brown WF. Age related changes in human thenar motor unit twitch contractile properties. J Appl Physiol 1997; 82: 93-101.

49. Campbell MJ, McComas AJ, Petito F. Physiological changes in ageing muscles. J Neurol Neurosurg Psychiatry 1973; 36: 174182.

50. Dengler R, Konstanzer A, Kuther G, et al. Amyotrophic lateral sclerosis: macro-EMG and twitch forces of single motor units. Muscle Nerve 1990; 13: 545-550.

51. Felice KJ. A longitudinal study comparing thenar motor unit number estimates to other quantitative tests in patients with amyotrophic lateral sclerosis. Muscle Nerve 1997; 20: 179-185.

52. Brown WF, Jaatoul N. Amyotrophic lateral sclerosis-electrophysiologic study (number of motor units and rate of decay of motor units). Arch Neurol 1974; 30: 242-248.
53. Stalberg E, Fawcett PRW. Macro EMG in healthy subjects of different ages. J Neurol Neurosurg Psychiatry 1982; 45: 870-878.

54. Dengler R, Stein RB, Thomas CK. Axonal conduction velocity and force of single human motor units. Muscle Nerve 1988; 11: 136145.

55. Dorfman LJ. The distribution of conduction velocities (DCV) in peripheral nerves: a review. Muscle Nerve 1984; 7: 2-11.

56. Lee RG, Ashby P, White DG. Analysis of motor conduction velocity in the human median nerve by computer simulation of compound muscle action potentials. Clin Neurophysiol 1975; 39: 225-237.

57. Thomas PK, Sears TA, Gilliatt RW. The range of conduction velocity in normal motor nerve fibres to the small muscles of the hand and foot. J Neurol Neurosurg Psychiatry 1959; 22: 175-181.

58. Stalberg EV, Trontelj JV. SFEMG findings in different disorders. In: Stalberg EV, Trontelj JV, eds. Single Fibre Electromyography. Old Woking: The Mirvalle Press Lid, 1979: 99-148.

59. Stalberg E. Use of single fiber EMG and macro EMG in study of reinnervation. Muscle Nerve 1990; 13: 804-813.

60. Stalberg E. Electrical microstimulation with single fiber electromyography: a useful method to study the physiology of the motor unit. J Clin Neurophysiol 1992; 9: 105-119.

61. Abbruzzese G, Dall'Agata D, Morena M, et al. Electrical stimulation of the motor tracts in cervical spondylosis. J Neurol Neurosurg Psychiatry 1988; 51: 796-802.

62. Merton PA. Scope of a technique for electrical stimulation of human brain, spinal cord, and muscle. Lancet 1982: 597-600.

63. Mills KR. Electrical stimulation over the human vertebral column: which neural elements are excited? Electroencephalogr Clin Neurophysiol 1986; 63: 582-589.

64. Plassman BL, Gandevia SC. High voltage stimulation over the human spinal cord: sources of latency variation. J Neurol Neurosurg Psychiatry 1989; 52: 213-217.

65. Bolton CF. Assessment of respiratory function in the intensive care unit. Can J Neurol Sci 1994; 21 : S28-S34.

66. Sonoo M, Stalberg E. The ability of MUP parameters to discriminate between normal and neurogenic MUPs in concentric EMG: analysis of the MUP 'thickness' and the proposal of 'size index'. Electroencephalogr Clin Neurophysiol 1993; 89: 291-303.

67. Brown WF. Needle electromyographic abnormalities in neurogenic and muscle diseases. $l \mathrm{~m}$ : Brown WF, ed.The Physiological and Technical Basis of Electromyography. Boston: Butterworth. 1984: 317-338.

68. Daube JR. Needle examination in clinical electromyography. Muscle Nerve 1991; 14: 685-700.

69. Howard JE, McGill KC, Dorfman LJ. Age effects on properties of motor unit action potentials: ADEMG analysis. Ann Neurol 1988; 24: 207-213.

70. Nandedkar SD, Barkhaus PE, Sanders DB, et al. Analysis of amplitude and area of concentric needle EMG motor unit action potentials. Electroencephalogr Clin Neurophysiol 1988: 69: 561-567.

71. Frontera WR, Meredith CN, O'Reilly KP, et al. Strength conditioning in older men: skeletal muscle hypertrophy and improved function. J Appl Physiol 1988; 64: 1038-1044.

72. Moon KL Jr, Genant HK, Helms CA, et al. Musculoskeletal applications of nuclear magnetic resonance. Radiology 1983; 147: 161-171.

73. Brooke $\mathrm{MH}$, Kaiser KK. Three "myosin adenosine triphosphate" systems: the nature of their $\mathrm{pH}$ lability and sulfhydryl dependence. J Histochem Cytochem 1970; 18: 670-672.

74. Peter JB, Barnard RJ, Edgerton VR, et al. Metabolic profiles of three fiber types of skeletal muscle in guinea pigs and rabbits. Biochemistry 1972; 11: 2627-2633. 